\title{
SiM
}

\section{Valuing and Rewarding Ecosystem Services From Rangelands}

\author{
By Neil D. MacLeod and Joel R. Brown
}

\section{On the Ground}

- Ecosystem services are the wide array of benefits that people gain from natural ecosystems but many are not paid for nor is their future supply guaranteed.

- Many attempts are being made to define, measure, and value these natural services in order to secure their future-many of these methods are theoretical.

- Finding practical ways to reward land managers for providing elevated levels of services and protecting the capacity of range resources to provide those services is a challenge-theory well precedes practice.

- Range landscapes typically encompass heterogeneous ecological units dominated by native vegetation and have the capacity to provide different levels of ecosystem services depending on both site features and local management.

- Ecological Site Descriptions are potentially valuable for organizing information related to management options to achieve ecosystem service objectives and provide benchmarks for stewardship rewards or compliance expectations.

Keywords: ecosystem services, stewardship, rangelands, Ecological Site Descriptions.

Rangelands 36(2):12-19

doi: 10.2111/RANGELANDS-D-13-00075.1

(C) 2014 The Society for Range Management

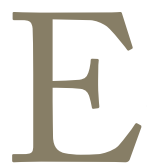
cosystem services are benefits that humankind gains from accessing natural ecosystems. For many years these services were something that both ranchers and the wider community largely took for granted but the recognition of their importance has grown rapidly as has the debate on how best to conserve and manage them. ${ }^{1}$ This particularly applies to privately grazed range- lands where the services extend beyond the extraction of food and fiber for sale to encompass an array of services including, for example, watershed integrity, biodiversity, and cultural and aesthetic values. Range and ecological sciences have supported a growing body of knowledge on the importance and complexities of ecosystem functions and their explicit links to human well-being, along with efforts to define and measure ecosystem services as a means of assigning values to natural capital. $^{2}$

Despite progress, our knowledge of the functional links between different types and intensities of management activity and the ecosystem services that range landscapes can provide remains incomplete, more so their value in functional or monetary terms. As a result, significant scope remains for their underprovision and social (externality) losses. Therefore, the definition, measurement, and valuation of ecosystem services are challenges for range science and economics for which novel solutions are emerging. But finding practical ways to reward rangeland managers for providing elevated levels of services and protecting the capacity of range resources to provide those services is perhaps a greater challenge-theory is well in advance of practice. This is particularly cogent for wildlands or shrublands, which are extremely vulnerable to ecological impairment through poor management practices but are also uniquely placed to deliver many valuable ecological services. In this article we consider a framework for delivering a broad range of ecosystem services from privately managed rangelands and canvass some ideas on how to establish practical reward and compliance schemes to support it.

\section{Ecosytem Services From Rangelands}

Range landscapes exhibit considerable diversity and are typically comprised of different ecological units that are dominated by native vegetation. Unlike most agricultural landscapes, rangelands are usually managed without the homogenizing effects of clearing, cultivation, and intensive application of inputs (e.g., exotic plants, fertilisers, and irrigation). They can provide levels of ecosystem services that are unique and otherwise expensive to replicate under other types of land use, but differ between sites and how they are managed. Range 
ecosystems offer challenges for research and management because of their highly variable structure and ecological function and feedbacks to disturbance. This challenge applies equally to viable management, reward and compliance schemes for rangeland-generated ecosystem services.

\section{The "Old" Economy}

The dominant economic use of range landscapes globally is extensive livestock grazing. This specialization towards harvesting range herbage by livestock and selling their progeny and other produce (e.g., milk, hides, and wool) reflects the prevailing market structure for rangeland-produced ecosystem services. Few if any well-established markets presently exist for services beyond those based on cropping or grazing values. The economic context of rangeland livestock production is also shaped by an ongoing chronic cost-price squeeze with declining real returns to the underlying ranch asset base. The traditional management response has been to raise productivity to offset the declining real price for ranch output and this has often involved increasing grazing pressure with further demands on the underlying ecosystem services. In the case of Australia, ranch productivity gains have failed to keep up for most of the past decade and ranch profits have stagnated for all but the most innovative operations. ${ }^{3}$ Therefore, the idea that ecosystem services might hold a tangible value beyond grazing opportunity and that the ranch revenue base might be profitably diversified through access to novel streams of stewardship payments carries considerable attraction for many ranchers.

\section{Environmental "Goods"}

Regardless of whether stewardship payments for a wider range of ecosystem services could offer a financial lifebuoy to a struggling ranching sector, range landscapes do provide a wide range of ecosystem services to both the ranch sector itself and the broader community. These services need to be recognized, valued, rewarded, or regulated in order to strike an appropriate balance between activities that promote the broad spectrum of ecosystem services and a profitable few for livestock production, and also address the wider scope of private and public interests.

To establish a practical framework to promote ecosystem services and support reward and compliance innovations it is useful to consider what types of services might be covered. While some early scholastic writing ${ }^{1}$ may have kick-started global thinking on the importance of natural capital to humankind, the Millennium Ecosystem Assessment (MA) of 2004 was a critical point in triggering a global effort to define the array and the importance of ecosystem services. ${ }^{4}$ The MA defined ecosystem services in four broad categories: provisioning, regulating, cultural, and supporting. Provisioning services are widely recognized as a source of directly consumable agricultural commodities. These are notably food and fiber, but there is increasing emphasis on other uses including amenity and other lifestyle dimensions. ${ }^{5}$ Some other provi- sioning services might include a repository of genetic material of use for recovery plantings in degraded pastures, sites for energy extraction, or supporting infrastructure. Commercial networks supporting the extraction and delivery of landscape provisioning services are well developed and the markets for these services have well-defined and regulated standards.

While regulating, cultural, and supporting services frequently involve no formal markets and are more difficult to measure and to value, they are increasingly recognized as important for contributing to the total value of rangeland ecosystems. Regulating services include the sequestration of atmospheric carbon by plants and soil to contribute to climate stabilization and pollution control, and are gaining an increasing interest from land managers, markets, and policy makers. In fact, payments for carbon regulation through appropriate management of vegetation and soils management is presently the most developed application of a formal market for a regulating ecosystem service. Cultural services are the benefits that people obtain through spiritual enrichment, cognitive development, and aesthetics, and are difficult to quantify because they are extremely subjective and can be the source of considerable controversy and conflict. Supporting services include provision by native vegetation of critical habitat and water cycling, and also have attributes that are amenable to quantification and creation of markets. An example includes the Bush Tender scheme in Australia that employs an open tender system to purchase conservation set asides of native vegetation from ranchers for defined periods. ${ }^{6}$

\section{Environmental "Bads"}

It is important to acknowledge that the ecosystem services that should be provided by many range landscapes have been seriously degraded through poor management practices. The range science literature is replete with examples of landscape dysfunction including soil structure decline and accelerated erosion, pasture decline, weed ingress, shrub encroachment, tree decline and habitat loss, wildlife species decline and extinction, salinity, loss of future access to genetic materials, and diminished landscape "amenity." 1 Moreover, the scale of the degradation and intensity of its impact is far from trivial. For example, an assessment of soil and vegetation resources of the Australian rangelands ( 75 million hectares) in the 1990s reported $32 \%$ of the grazing lands to be moderately degraded (i.e., soil deterioration and increased undesirable pasture species) with a further $12 \%$ severely degraded (i.e., severe soil deterioration and predominance of undesirable pasture and shrub species). ${ }^{7}$

\section{Duty of Care}

When considering potential rewards for providing elevated levels of environmental services, the question arises of the appropriate benchmark for acceptable management practices. To what point should the community hold a reasonable expectation that private ranchers and public land managers will exercise an appropriate "duty of care" to protect the capacity 
of their landscape resources to produce ecosystem services into perpetuity, and below which penalties for serious impairment might apply. Rewards or financial assistance would normally only be available for management activities that go beyond the mandated duty of care, as such incentives would not be appropriate to simply induce managers to meet their obligations to protect base levels of ecosystem services. The broad principle of this delineation between private and public financial responsibility for protecting ecosystem services has been generally accepted in Australia, although its application in practice remains challenging. ${ }^{8}$

\section{"Ecosystem Service-Friendly" Landscapes}

Regardless of where any private-public good benchmark for landscape conservation might be finally set or how compensation schemes might work in practice, a key question remains of what management activities might actually be required to secure high levels of ecosystem services from rangelands. Critically, many of the landscape elements that have a potentially high value to the wider community (e.g., rich biodiversity and "amenity" options) may offer little direct (provisioning) value to private managers. Moreover, because the desired level of ecosystem services cannot be technically or economically protected exclusively within the limited network of public conservation reserves within rangeland regions, it is inevitable that most will have to be sourced from privately managed ranch land, which will necessarily influence how this land is managed in the future.

Proposals for the sustainable use of privately owned grazing land often call for a balance between the imperatives to conserve local ecosystem services and the need to ensure the economic viability of ranch enterprises. While this concept may seem pragmatic, fulfilling it presents a serious challenge for the managers of contemporary livestock production systems. We explore the nature and scope of this challenge using, as an example, a set of best-practice landscape design principles that have been advanced to guide private land managers' decision-making for the sustained use of Australian savanna landscapes under grazing. ${ }^{9}$

\section{Design Principles and Thresholds}

The landscape design principles cover the conservation of soils, pastures, trees, watercourses and riparian lands, and wildlife habitat within a whole ranch management context. They include ecological thresholds below which some important ecosystem functions may become increasingly dysfunctional. "Conservation" spans more than just provisioning services and extends beyond simply conserving "production" resources (i.e., soil and pasture biomass) to accommodate the complexity of a well-functioning landscape and the wider set of community interests in all of the ecological services that rangelands can offer. The full set of landscape design principles and thresholds is quite detailed. We summarize the key elements as follows (thresholds where defined in brackets represent either points beyond which significant impairment of ecological processes may occur or minimum standards that have been established by the community):

- Maintaining or re-establishing riparian buffers (40-100 $\mathrm{m})$, preferably fenced out and managed for controlled livestock access;

- Retaining or re-establishing viable stands of vegetation (5-10 ha) on all major land types;

- Managing grazing and fire regimes to retain high levels of ground cover ( $<30 \%$ bare area), also characterized by a strong perennial grass structure ( $>70 \%$ of landscape);

- Retaining minimum levels of tree cover across the landscape (30\% woodland structure for grassy woodland);

- Limiting intensive development activities (e.g., sown pastures, cultivation, and fertilizer) within the landscape $(<30 \%$ total area) and maintaining vegetation or land use buffers between these intensive uses and areas of higher conservation values;

- Protection of vegetation on potential recharge areas where a salinity hazard exists; and

- Linkages of vegetation established between these elements across the landscape.

\section{Applying the Landscape Design Principles}

To explore the potential impact of creating ecosystem service-friendly landscapes on the productivity and profitability of private ranches, one of the authors has previously applied computer simulation modelling to synthetically apply the design principles to the landscapes of four working ranches located in Queensland and New South Wales. ${ }^{10}$ The ranches represent median size crop-livestock and specialized livestock operations that adhere to best-practice herd and grazing management. Some characteristics of the four ranches are summarized in Table 1.

The following assessment was applied:

1) Resource and land use maps were prepared for each ranch and supplemented with field assessment of tree species density and health, soil type and condition, pasture species and condition, and wildlife habitat.

2) This data was summarized to provide an overview of their ecological status under present management.

3) The present status of the ranches was contrasted with an alternative "synthetically" constructed state that is consistent with the design principles and thresholds.

4) Changed cropping and grazing opportunity was based on changes to areas placed under conservation to protect riparian areas, augment woodland for viability and core habitat needs, and to ensure connectivity between habitat elements.

5) An assessment was conducted of the production and financial consequences of the ranches operating with the revised crop and pasture areas under the reconfigured landscapes, and an estimate was obtained of the capital investment required to implement the changes. 
Table 1. Summary features of four commercial ranches used to assess the application of the landscape design principles advanced by McIntyre et al ${ }^{9}$

\begin{tabular}{|c|c|c|c|c|c|c|c|}
\hline Location & $\begin{array}{c}\text { Enterprise } \\
\text { type }\end{array}$ & $\begin{array}{l}\text { Total ranch } \\
\text { area }(\mathrm{Ha})\end{array}$ & $\begin{array}{c}\text { Total livestock } \\
\text { carried (AE) }\end{array}$ & $\begin{array}{l}\text { Total crop } \\
\text { area }(\mathrm{Ha})\end{array}$ & $\begin{array}{c}\text { Sown pasture } \\
\text { area }(\mathrm{Ha})\end{array}$ & $\begin{array}{c}\text { Existing } \\
\text { woodland } \\
\text { area (Ha) }\end{array}$ & $\begin{array}{c}\text { Permanent } \\
\text { labor force } \\
\text { (No.) }\end{array}$ \\
\hline $\begin{array}{l}\text { Mundub- } \\
\text { bera }\end{array}$ & $\begin{array}{l}\text { Livestock } \\
\text { only }\end{array}$ & 10,500 & 2,000 & Nil & 3,500 & 5,000 & 2 \\
\hline Mitchell & $\begin{array}{l}\text { Live- } \\
\text { stock- } \\
\text { crops }\end{array}$ & 4,500 & 900 & 500 & 375 & 3,625 & 2 \\
\hline $\begin{array}{l}\text { Moree } \\
\text { Plains }\end{array}$ & $\begin{array}{l}\text { Live- } \\
\text { stock- } \\
\text { crops }\end{array}$ & 2,200 & 600 & 1,000 & 460 & 740 & 2 \\
\hline $\begin{array}{l}\text { Goondi- } \\
\text { windi }\end{array}$ & $\begin{array}{l}\text { Live- } \\
\text { stock- } \\
\text { crops }\end{array}$ & 12,100 & 1,700 & 2,700 & 7,000 & 2,400 & 3 \\
\hline
\end{tabular}

$\mathrm{AE}$ indicates adult equivalents ( $1 \mathrm{AE} \sim 450 \mathrm{~kg}$ nonpregnant, nonlactating cow).

\section{Landscape Rehabilitation Task}

The general finding for landscape health on the four ranches was that the pasture and soil resources were in good condition (e.g., good tussock structure, ground cover, and soil surface condition, and limited erosion). Resource degradation was generally localized to particular soil and vegetation types and sites that are prone to damage through overgrazing and physical disturbance. Some wider-scale resource damage had occurred in the past (e.g., after initial land clearing or prior overstocking), but had been stabilized, suggesting that grazing and crop management was good on all of the ranches. That is, a shift had already occurred towards a more sustainable management of the landscape elements that is strongly linked to provisioning ecosystem services. However, the condition of the elements, which are strongly linked to the other forms of ecosystem services, including tree populations, watercourses and riparian areas, and wildlife habitat and corridors, was less benign. This is reflected in the scale of the revegetation and protection tasks required to re-align the landscapes of the four ranches with the landscape design principles and thresholds (Table 2).

\section{Economic Impact}

The restoration tasks to re-align the landscapes of the four ranches to provide a wider array of ecosystem services are considerable (Table 3) in terms of capital outlays to implement the changes and the annual cost of lost cropping and grazing opportunities and ranch income. In this case the permanent decline in annual net profits ranges from $20 \%$ to $80 \%$ and il- lustrates that even small changes in crop areas and herd numbers can have large impacts on ranch profitability when profit margins are already low. Given that the four ranches represent commercial operations employing best-practice crop and herd management systems, this outcome highlights the significant challenges for the wider implementation of ecologically desirable management practices on private ranch land.

These projections of negative economic outcomes for extensive remedial environmental work on private grazing lands are not unique to rangeland livestock systems, but are often downplayed by environmental interests as a barrier to adoption in favour of nonfinancial issues (e.g., lack of technical information, spillovers, etc.) despite their intuitively obvious impact. ${ }^{11}$ This does not deny the positive contribution that the provisioning services of the pasture and soil resources are making to the profitability of the four ranches, or that retaining trees to promote biodiversity or wildlife habitat may hold significant values to the wider community. The main issues for putting an ecological balance back into production landscapes remain the loss of the tree and shrub components from the vegetation matrix, and the fact that private land managers receive little reward for replacing them under present market structures. ${ }^{11}$

\section{Moving Forward}

Practical people, like ranchers, are generally disinclined to engage in serious debate about technologies or practices with limited scope for profitable application. The physical task and the financial sacrifices required to restore the capacity of pro- 
Table 2. Resource task required to reconfigure the landscapes of four commercial ranches to meet minimum thresholds of landscape attributes as identified by McIntyre et al ${ }^{9}$

\begin{tabular}{|l|c|c|c|c|c|c|}
\hline Location & $\begin{array}{c}\text { Augmented } \\
\text { woodland } \\
\mathbf{( H a )}\end{array}$ & $\begin{array}{c}\text { Riparian } \\
\text { buffers } \\
\mathbf{( H a )}\end{array}$ & $\begin{array}{c}\text { Riparian } \\
\text { fencing } \\
\mathbf{( K m )}\end{array}$ & $\begin{array}{c}\text { Off-stream } \\
\text { water } \\
\text { points (No.) }\end{array}$ & $\begin{array}{c}\text { Total } \\
\text { regenerated* } \\
\text { (\%) }\end{array}$ & $\begin{array}{c}\text { Total } \\
\text { planted* } \\
\mathbf{( \% )}\end{array}$ \\
\hline Mundubbera & 2,292 & 418 & 140 & 16 & 60 & 40 \\
\hline Mitchell & 479 & 157 & 16 & 3 & 50 & 50 \\
\hline Moree Plains & 247 & 23 & 47 & 8 & 50 & 50 \\
\hline Goondiwindi & 1,230 & 845 & 37 & 10 & 50 & 50 \\
\hline
\end{tabular}

*Estimated natural tree regeneration capacity of existing landscape units at the rehabilitation sites.

Table 3. Land use and annual net profit change associated with a hypothetical reconfiguration of the landscapes of four commercial ranches to meet minimum thresholds of landscape attributes as identified by McIntyre et al ${ }^{9}$

\begin{tabular}{|c|c|c|c|c|c|c|}
\hline Location & $\begin{array}{c}\text { Crop } \\
\text { area } \\
\text { change } \\
(\mathrm{Ha})\end{array}$ & $\begin{array}{c}\text { Sown } \\
\text { pasture area } \\
\text { change }(\mathrm{Ha})\end{array}$ & $\begin{array}{c}\text { Total livestock } \\
\text { carried change } \\
\text { (AE) }\end{array}$ & $\begin{array}{c}\text { Net profit } \\
\text { change } \\
(\$ 1,000[\$ A U])\end{array}$ & $\begin{array}{l}\text { Net profit } \\
\text { change } \\
(\%)\end{array}$ & $\begin{array}{c}\text { Total capital } \\
\text { cost } \\
(\$ 1,000[\$ A U])\end{array}$ \\
\hline Mundubbera & NA & -670 & -465 & -87 & -77 & 1,700 \\
\hline Mitchell & -6 & -375 & -100 & -176 & -54 & 54 \\
\hline Moree Plains & -57 & -52 & -110 & -123 & -30 & 300 \\
\hline Goondiwindi & -166 & $-1,260$ & -210 & -87 & -19 & 1,180 \\
\hline
\end{tabular}

$\mathrm{AE}$ indicates adult equivalents ( $\mathrm{AE} \sim 450 \mathrm{~kg}$ nonpregnant, nonlactating cow). AU $\$ 1.00=$ US $\$ 0.90$ (valued on 2 March 2014).

duction landscapes to generate a wide spectrum of ecosystem services is a formidable barrier to moving forward, but the physical problems are not going to conveniently disappear because of short-term economic inertia. A pragmatic solution to breaking the impasse on management change would involve a two-pronged approach, including 1) immediately striving to implement those components of the ecological principles that can be accommodated by existing range enterprises with or without public support (e.g., Landcare and National Heritage Trust grants in Australia and Environmental Quality Improvement Program support in the United States), and 2) putting in place the institutions and policies that will support the desirable changes in landscape management over a longer period of time. We now make a few suggestions for getting started and breaking some of the impasse on adoption.

\section{Measuring and Monitoring Ecosystem} Services

Challenges

"If it can't be measured it won't get done." It is hard to deny this simple truth and rewarding private land managers who provide or protect high levels of ecosystem services requires implementing practical measures that accurately identify the various ecosystem services, measure the level of those services, and value them realistically. Unfortunately, while intuitively obvious, these are not trivial issues in either theory or practice. The concepts of ecosystem services were initially advanced by ecologists to draw attention to the benefits of conserving natural ecosystems, particularly in the face of rapid economic development and human population growth, and these were described in fairly abstract terms to get ideas across to a non-ecological audience. ${ }^{1,4}$ While many scholarly 


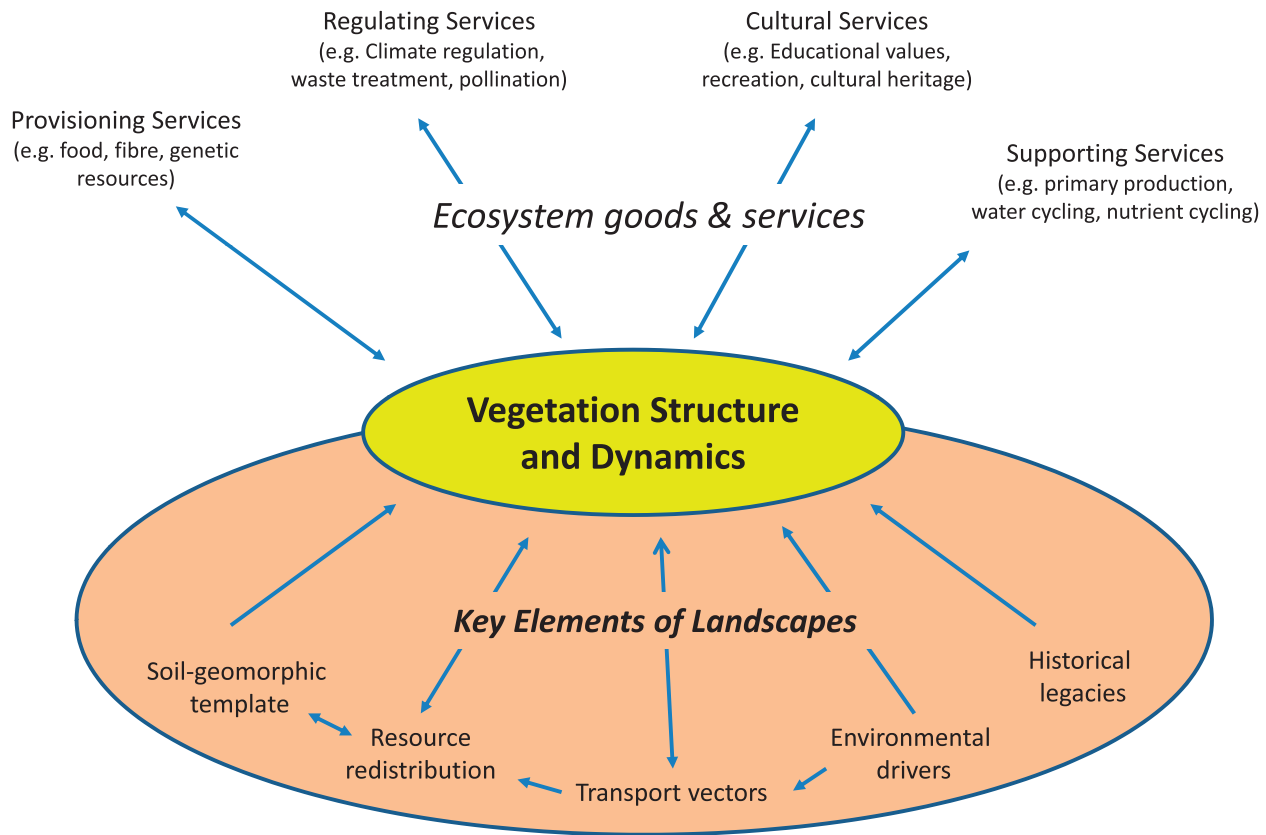

Figure 1. Linkages between landscape elements, vegetation structure and dynamics, and the provision of ecosystem services (after Peters et al. ${ }^{15}$ ).

attempts have been made to specify individual ecosystem service components, this remains a hard task. For example, definitions of ecosystem services commonly lump together an array of natural processes, products, and benefits that are hard to quantify, let alone attribute values to. ${ }^{6}$

Markets are emerging for some services from which values can be directly measured (e.g., carbon sequestration, water, and habitat), but quantification and valuation remains complicated for many forms of services when, for example, they comprise mixes of market and nonmarket values, are intermediate (e.g., nutrient cycling and wildlife habitat) to other services (e.g., provisioning services for crops and hunting values) or are tied up in aesthetic values (e.g., scenic beauty and wilderness). Unless we continue to seek out these values, the likelihood of implementing optimal levels of management to conserve or expand the level of ecosystem services generated within rangelands remains limited. As we noted before, quantification and valuation of ecosystem services present unique challenges and a growing literature exists on both the theoretical and practical nature of these challenges and options, especially for creating viable commercial markets for services. ${ }^{2}$ It is beyond the scope of this paper to address the many issues that are canvassed within this literature-we just note that these are a critical basis for advancing feasible stewardship and compliance schemes.

\section{Linking Management to Site Outcomes}

Regardless of how they are eventually identified and valued, a significant challenge for establishing effective reward and penalty schemes is attributing clear linkages between the level and timing of management actions and specific site outcomes. Ranchers will expect to be rewarded for their ef- forts and equity demands that rewards be in line with the quality of the services that are provided. Range ecosystems and their underlying ecological processes are highly context dependent (e.g., resource endowments, ecological health, impacts of adjacent land uses, and season) and vary significantly across spatial and temporal scales. ${ }^{12}$ Most empirical estimates of ecosystem service values relate to a few discrete measurement sites and contexts and cannot be readily transferred to other sites and contexts without considered qualification. To be genuinely useful to supporting reward or compliance schemes, measures of service values necessarily have to be site specific and reflect both the spatial heterogeneity of the service-generating potential of range landscapes and the specific management actions that underpin it.

\section{Vegetation Structure and Dynamics}

A systematic approach is needed for describing the dynamics of range ecosystems under various management actions and the accompanying changes in those services. Fortunately, there is a vast body of rangeland ecology and management research and practice available for establishing the necessary links and a core intermediary role is played by local vegetation structure and dynamics as depicted in Figure 1. The ecological processes that are associated with five key landscape element-soils/geology, resource redistribution, transport vectors, environmental drivers (e.g., climate), and historical legacies-interact to determine vegetation structure and dynamics with resulting effects on various ecosystem services. ${ }^{13}$ Different management practices can be employed to mediate those interactions and change the vegetation structure and dynamics which, in turn, will influence the provision of ecosystem services from a particular site. What is required to ex- 
ploit this central linkage between management manipulation of the vegetation structure and dynamics at specific sites and ensuing ecosystem services, is a systematic framework for assessing the state and condition of local vegetation in order to determine its capacity to generate ecosystem services. Such a framework will also require the capacity to assess the trend in condition through time, which is a necessary element of any practical reward or compliance system. Ecological Site Descriptions (ESD) offer one such framework with the practical advantage that the construct is already operating under field conditions within the United States. ${ }^{14}$

\section{Ecological Site Descriptions}

The ESD system classifies landscapes into ecological sites that have specific characteristics that give a consistent response to natural disturbance and management actions. ${ }^{15} \mathrm{Be}-$ yond providing general descriptions of a site (climate, geology, soil properties, topography, and hydrology), ESDs employ "state and transition" logic to describe various ecological state indicators and vegetation dynamics. Critically they include predictors of the diversity and quality of the various ecosystem services on offer under each state and suggest management actions that are necessary to maintain or achieve each state. ${ }^{2}$ Beyond piggybacking on an existing investment, the ESD approach allows a unique set of ecosystem services to be assigned to specific rangeland units and there is sufficient ecological knowledge available to commence attributing different levels of ecosystem services to those units. The state and transition models within an ESD offer a sound platform for quantifying ecosystem services at a site because the states are typically represented by a gradient of change in vegetation structure (i.e., grass:shrub:tree balance) and other site features that can be detected using a variety of monitoring protocols ranging from direct field sampling through to remote sensing. These states can provide benchmarks for stewardship rewards and compliance expectations. For example, land managers who might enter into contracts to increase the amount of ecosystem services that are to be provided by a defined rangeland unit moving from one state to another can lodge management plans in the contractual agreements that contain the specific practices to be employed, guidelines for planning, and protocols for verification.

\section{Conclusion}

Rangelands cover vast areas and generate a wide array of valuable ecosystem services. Only a subset of these services is presently compensated and at the private ranch level, at least, these are largely confined to provisioning services that underpin present economic production. Many other forms of ecosystem services, including regulating, supporting, and cultural services, are neither recognized nor rewarded even though they carry considerable value to the community. As a result they are undersupplied under present patterns of land use, which is not necessarily optimal from a community perspective. Balance in the use of range resources and their con- tinued capacity to provide high levels of ecosystem services is clearly desirable and sound stewardship of those resources rightly deserves to be rewarded. However, this is yet to be practically achieved under the existing patterns of markets and institutions.

Change is coming, albeit slowly, and environmental stewardship schemes are emerging, including such diverse environmental services as provision of clean water, carbon sequestration, pollination services, and enhanced protection and availability of habitat for scarce and endangered species. The challenge remains of how to measure ecosystem services in a consistent manner and in a form that can support the establishment of management plans and verification protocol to underpin future contractual agreements to increase the amount of ecosystem services from a particular rangeland unit. We have noted the potential for Ecological Site Descriptions to support such development. Whatever emerges in practice, society will need fairly deep pockets to support functioning reward and compliance schemes, given the magnitudes of the ecological values involved and potential sacrifices to profitability of private land management if compliance is otherwise mandated without adequate rewards.

\section{References}

1. Costanza, R., R. d’Arge, R. de Groot, S. Farber, M. Grasso, B. Hannon, K. Limberg, S. Naeem, R. O’Neill, J. Paruelo, R. Raskin, P. Sutton, and M. van den Belt. 1997. The value of the world's ecosystem services and natural capital. Nature 387:253-60.

2. Brown, J. R., and N. D. MacLeod. 2011. Measuring ecosystem services from rangelands. Rangeland Journal 33:99-108.

3. McCosker, T., D. McLean, and P. Holmes. 2010. Northern beef situation analysis 2009. Project report B.NBP.0518. Sydney, NSW, Australia: Meat and Livestock Australia. 74 p.

4. Millennium Ecosystem Assessment. 2005. Ecosystems and human well-being: synthesis. Washington, DC, USA: Island Press. 146 p.

5. Tanaka, J. A., L. A. Torell, and N. R. Rimbey. 2005. Who are these public land ranchers and why are they out there? The Western Economics Forum 4(2):14-20.

6. Whitten, S., and D. Shelton. 2005. Market for ecosystem services in Australia: practical design and case studies. Canberra, ACT, Australia: Commonwealth Scientific and Industrial Research Organisation Sustainable Ecosystems. 30 p.

7. Tothill, J. C. and C. Gillies. 1993. The pasture lands of northern Australia. TGS Occasional Publication No. 5. Brisbane, QLD, Australia: Tropical Grasslands Society of Australia. $115 \mathrm{p}$.

8. ANZECC. 2000. National framework for the management and monitoring of Australia's native vegetation. Canberra, ACT, Australia: Australian and New Zealand Environment and Conservation Council. 70 p.

9. McIntyre, S, J. G. McIvor, and N. D. MacLeod. 2000. Principles for sustainable grazing in eucalypt woodlands: landscape- 
scale indicators and the search for thresholds. In: P. Hale, D. Moloney, and P. Sattler [EDs.]. Management for sustainable ecosystems. Brisbane, Q1d, Australia: Centre for Conservation Biology, University of Queensland, Brisbane. p. 92-100.

10. MacLeod, N. D. and J. G. McIvor. 2003. Evaluating landscape design principles for optimising biodiversity in grazed savannas. In: N. Allsop, A. R. Palmer, S. J. Milton, K .P. Kirkman, G. I. H. Kerley, C. R. Hurt, and C. J. Brown [eds.]. Proceedings of 7th International Rangelands Congress; 26 July-1 August 2003; Durban, South Africa. Grahamstown, Eastern Cape, Republic of South Africa: Grasslands Society of Southern Africa. p. 1961-1963.

11. Pannell, D. J. 1999. Explaining non-adoption of practices to prevent salinity in Western Australia. SEA Working Paper 99/08. Agricultural and Resource Economics. Nedlands, WA, Australia: University of Western Australia. 9 p.

12. Ludwig, J. A., And D. J. Tongway. 1997. A landscape approach to rangeland ecology. In: J. A. Ludwig, D. J. Tongway, D. Freudenberger, J. C. Noble, and K. C. Hodgkinson [EDs.]. Landscape ecology: function and management. Melbourne, VIC, Australia:
Commonwealth Scientific and Industrial Research Organisation. p. 1-12.

13. Havstad, K. M., D. P. Peters, R. Skaggs, J. R. Brown, B. T. Bestelmeyer, E. Fredrickson, J. E. Herrick, and J. Wright. 2007. Ecological services to and from rangelands of the United States. Ecological Economics 64:261-268.

14. Bestelmeyer, B. T., and J. R. Brown. 2010. An introduction to the special issue on ecological sites. Rangelands 32:3-4.

15. Peters, D. P. C., B. T. Bestelmeyer, J. E. Herrick, E. L. Fredrickson, H. C. Monger, and K. M. Havstad. 2006. Disentangling complex landscapes: new insights to forecasting arid and semiarid system dynamics. Bioscience (56)491-501.

Authors are Principal Research Scientist, Ecosystem Sciences, Commonwealth Scientific and Industrial Research Organisation (CSIRO), Brisbane, QLD 4102, Australia, neil.macleod@csiro. au (MacLeod); and Range Management Specialist, USDA Natural Resources Conservation Service, Las Cruces, NM 88003, USA (Brown). 